\title{
Estudantes do ensino superior com Transtorno do Espectro Autista: uma revisão integrativa da literatura brasileira
}

\author{
Higher education students with Autism Spectrum Disorder: an integrative \\ review of brazilian literature
}

\section{Estudiantes de educación superior con Trastorno del Espectro Autista: una revisión integradora de la literatura brasileña}

Daniele de Oliveira Camalionte

Mestranda na Universidade Estadual Júlio Mesquita Filho, Marília, SP, Brasil

E-mail: dani.camalionte@gmail.com ORCID: https://orcid.org/0000-0003-4663-8782

\section{Letícia Kondo}

Mestranda na Universidade Estadual Júlio Mesquita Filho, Marília, SP, Brasil

E-mail: leticiakondo_k@hotmail.com ORCID: https://orcid.org/0000-0002-5665-2900

\section{Aila Narene Dahwache Criado Rocha}

Professora doutora na Universidade Estadual Paulista Júlio Mesquita Filho, Marília, SP, Brasil

E-mail: aila.rocha@unesp.br ORCID: https://orcid.org/0000-0001-6186-875X

Recebido em 18 de fevereiro de 2021

Aprovado em 06 de maio de 2021

Publicado em 27 de maio de 2021

\section{RESUMO}

Com o crescente número de estudantes diagnosticados com Transtorno do Espectro Autista matriculados no Ensino Superior, esta Revisão Integrativa da Literatura objetivou analisar o processo de formação universitária do estudante com Transtorno do Espectro Autista, com ênfase em seu acesso, ingresso e permanência no Ensino Superior nas instituições educacionais brasileiras. Levando-se em conta o objetivo mencionado da pesquisa, as bases de dados Portal Regional da Biblioteca Virtual em Saúde Scientific Electronic Library Online e Periódicos da Coordenação de Aperfeiçoamento de Pessoal de Nível Superior foram consultadas. Na amostragem obtida, foram recuperados 7 artigos que atenderam aos critérios de inclusão e exclusão, sendo estes considerados aptos à análise. A partir da leitura dos estudos, identificaram-se barreiras para a inclusão e permanência dos estudantes diagnosticados com Transtorno do Espectro Autista, no contexto acadêmico, bem como possíveis estratégias foram apontadas para melhoria na acessibilidade. Conclui-se, portanto, haver uma lacuna na literatura nacional sobre intervenções baseadas em evidências especificamente projetadas para os estudantes universitários com Transtorno do Espectro Autista, no Brasil.

Palavras-chave: Educação Especial; Ensino Superior; Transtorno do Espectro Autista.

\section{ABSTRACT}

According to the growing number of students diagnosed with Autistic Spectrum Disorder (ASD) reaching Higher Education, this Integrative Literature Review aimed to analyze the 
http://dx.doi.org/10.5902/1984686X64322

process of university education of students with ASD with an emphasis on their access, admission and permanence in Higher Education in institutions Brazilian educational institutions. Taking into account the mentioned objective of the research, the databases VHL Regional Portal, SciELO and CAPES Journals were consulted, using the following descriptors to search for studies: higher education, higher education, university, autism, autistic spectrum, autistic disorder. In the sample obtained, 7 articles were retrieved that met the inclusion and exclusion criteria, which were considered suitable for analysis. From reading the studies, barriers were identified for the inclusion and permanence of students diagnosed with ASD in the academic context, as well as, possible strategies were pointed out to improve accessibility. Therefore, a gap is concluded in the national literature on evidence-based interventions specifically designed for university students with ASD in Brazil.

Keywords: Special education; University education; Autistic Spectrum Disorder.

\section{RESUMEN}

Con el creciente número de estudiantes diagnosticados con Trastorno del Espectro Autista matriculados en la Educación Superior, esta Revista Integrativa de la Literatura tuvo como objetivo analizar el proceso de formación universitaria de los estudiantes con Trastorno del Espectro Autista, con énfasis en su acceso, admisión y permanencia en la Educación Superior en la educación brasileña. Instituciones. Teniendo en cuenta el mencionado objetivo de la investigación, se consultaron las bases de datos Portal Regional de la Biblioteca Virtual en Salud Biblioteca Electrónica Científica Online y Publicaciones Periódicas de la Coordinación para el Perfeccionamiento del Personal de Educación Superior. En el muestreo obtenido se recuperaron 7 artículos que cumplieron con los criterios de inclusión y exclusión, los cuales se consideraron aptos para el análisis. A partir de la lectura de los estudios, se identificaron barreras para la inclusión y permanencia de los estudiantes diagnosticados con Trastorno del Espectro Autista, en el contexto académico, así como se señalaron posibles estrategias para mejorar la accesibilidad. Se concluye, por tanto, que existe un vacío en la literatura nacional sobre intervenciones basadas en evidencia diseñadas específicamente para estudiantes universitarios con Trastorno del Espectro Autista, en Brasil.

Palabras clave: Educación Especial; Educación Superior; Trastorno del Espectro Autista.

\section{Introdução}

A Política Nacional de Educação Especial na Perspectiva da Educação Inclusiva (BRASIL, 2008) aponta como parte do público-alvo da Educação Especial o Transtorno Global do Desenvolvimento, composto pelos indivíduos que apresentam alterações qualitativas das interações sociais recíprocas e na comunicação, tendo um repertório de interesses e atividades restritas, as quais podem ser estereotipadas e repetitivas. 
Em 2012, foi sancionada a Lei oㅜ 12.764, instituindo a Política Nacional das pessoas com Transtorno do Espectro Autista (TEA), considerando todos os sujeitos com deficiência persistente, clinicamente significativa, da comunicação e das interações sociais, marcadas pelas dificuldades de comunicação verbal e não verbal; de reciprocidade social; em desenvolver e manter relações apropriadas ao seu nível de desenvolvimento, podendo exibir alguns padrões comportamentais sensoriais incomuns e ter excessiva aderência a rotinas e padrões de comportamento ritualizados (BRASIL, 2012).

Em 2013, após a publicação da DSM-5, o autismo passa também a ser denominado TEA, pela nomenclatura, para definir os indivíduos que revelavam transtorno do neurodesenvolvimento (APA, 2013).

Dados presentes na pesquisa Silva e colaboradores (2019), baseados em levantamentos quantitativos do Instituto Nacional de Estudos e Pesquisas Educacionais Anísio Teixeira (INEP), órgão vinculado ao Ministério da Educação, mostram que o número de matrículas de universitários com TEA sofreu uma significativa ascensão, em 2011 e 2012, atingindo pico no ano de 2013, com posterior redução e estabilização até 2016.

Nesse mesmo contexto, o estudo realizado por Santos e Elias (2018), a partir dos microdados do censo escolar, afirma que o número de matrículas dos estudantes diagnosticados com TEA, no Brasil, sofreu um crescimento superior nos últimos anos, em comparação com outras deficiências. Houve aumento nas matrículas desde a Educação Infantil aos anos iniciais do Ensino Fundamental, entretanto, assistiu-se à queda nas matrículas referentes aos anos finais do Ensino Fundamental e no Ensino Médio.

Os resultados do trabalho de Santos e Elias (2018) sinalizam o alto índice de evasão escolar. Entre as possíveis causas de evasão, foi identificado que apenas um pequeno percentual desse público frequentava o Atendimento Educacional Especializado (AEE), de forma que a falta de apoio no processo de escolarização de estudantes com TEA demonstrou poder ser uma das razões pela qual há grande índice de evasão.

A constatação de que apenas um pequeno percentual de estudantes dos anos finais de escolarização tenham recebido $A E E$ pode estar relacionada aos desafios da inclusão de estudantes com necessidades educacionais especiais que vivenciaram um período transitório na legislação voltada à Educação Especial, no Brasil (ROSA; SQUASSIONI; MATSUKURA, 2019).

Todavia, com o crescimento contínuo do número de estudantes diagnosticados com TEA matriculados na Educação Infantil e no Ensino Fundamental, estima-se que o número 
http://dx.doi.org/10.5902/1984686X64322

de estudantes com TEA no Ensino Superior (ES) aumentará nos próximos anos (DONATTI; CAPELLINI, 2018; SILVA et al., 2019; OLIVATI; LEITE, 2019).

Este estudo corrobora o descrito na Lei Brasileira de Inclusão (2015), a qual compreende a educação como um direito de todos, garantido por um sistema educacional inclusivo em todos os níveis, a fim de oferecer o maior desenvolvimento possível de talentos e habilidades (físicas, sensoriais, intelectuais e sociais), respeitando as características, interesses e necessidades de aprendizagem de cada estudante. Em relação ao ES, a Lei Brasileira de Inclusão estabelece que o acesso deve ser promovido em igualdade de oportunidades e condições com as demais pessoas, por meio de medidas individualizadas e coletivas, não apenas para o desenvolvimento acadêmico, mas também para as questões sociais, favorecendo o acesso, a permanência, a participação e a aprendizagem do estudante com TEA (BRASIL, 2015).

O Programa INCLUIR (BRASIL, 2008) busca implantar a política de Educação Especial na perspectiva de educação inclusiva no ES e propõe ações de acesso e permanência de pessoas com deficiência nas Instituições Federais (IFES), sendo o seu objetivo principal fomentar a criação e a consolidação de núcleos de acessibilidade nas IFES, eliminando possíveis barreiras comportamentais, pedagógicas, arquitetônicas e de comunicação. "Porém, tais benefícios, na atualidade, restringem-se as IFES, cabendo às demais instituições públicas - estaduais ou municipais - a deliberação de fomento para ações dessa natureza pela gestão administrativa" (CIANTELLI; LEITE, 2016, p. 426).

Ainda que possa ser constatado um crescente número de estudos sobre universitários com TEA nas Instituições de Ensino Superior (IES), nos últimos anos, no Brasil, uma pequena gama de pesquisadores brasileiros procurou identificar as necessidades específicas desses estudantes, bem como os serviços institucionais que são oferecidos a eles (DONATTI; CAPELLINI, 2018; FISCHER, 2019; OLIVATI; LEITE, 2019, SILVEIRA; DONIDA; SANTANA, 2020).

Tendo em vista a Política Nacional de Educação Especial na perspectiva da Educação Inclusiva (BRASIL, 2008), que pontua a transversalidade da Educação Especial e orienta suas ações no ES, o acesso, a permanência e a participação dos estudantes devem ser garantidos pelas Instituições, por meio da organização de serviços e disponibilização de recursos para a participação efetiva do estudante, no contexto acadêmico, rompendo barreiras arquitetônicas, comunicacionais, de informação, tecnológicas e atitudinais. Essas medidas devem estar garantidas nas diferentes etapas da vida do estudante no ES, ou seja, 
http://dx.doi.org/10.5902/1984686X64322

envolvem ações desde os processos seletivos, no acolhimento e avaliações de suas necessidades, no momento de seu ingresso, até a garantia de igualdade de participação em todas as atividades que envolvam sua trajetória no ES. Para tanto, destaca-se o AEE como um dos serviços que devem ser disponibilizados nas IES, em forma de núcleos de acessibilidade, de sorte a oferecer o suporte e apoio necessários aos estudantes com deficiência (BRASIL, 2013a).

Nesse contexto, pactua-se com as autoras Ciantelli e Leite (2016) o conceito mais amplo acerca da acessibilidade, compreendendo os diversos aspectos envolvidos no termo, tais como físicos, instrumentais metodológicos, comunicacionais, programáticos e atitudinais, capazes de favorecer as pessoas com deficiência a usufruir em condições de igualdade diversas instâncias sociais, incluindo a educacional.

Felizmente, existe uma base de pesquisa emergente no Brasil que objetiva investigar a presença e a inclusão de estudantes com TEA no ES, visando a compreender e atender às suas necessidades individualizadas (DONATTI; CAPELLINI, 2018; FISCHER, 2019; OLIVATI; LEITE, 2019, SILVEIRA; DONIDA; SANTANA, 2020).

No cenário internacional, Kuder e Accardo (2017) fizeram uma revisão sistemática da literatura sobre os programas e serviços projetados para atender às necessidades de estudantes com TEA. Ambos os autores sugeriram que serviços de apoio não acadêmicos especializados são eficazes para satisfazer essas necessidades, que muitas vezes são exclusivas de estudantes universitários com TEA. Segundo o estudo, esses apoios precisam ser individualizados, a fim de contemplar as singularidades específicas dos estudantes.

Em outro estudo de revisão sistemática, feito por Anderson e colaboradores (2019), buscou-se examinar a eficácia das intervenções realizadas em pesquisas internacionais destinadas aos universitários com TEA, as quais, também, evidenciaram achados próximos a Kuder e Accardo (2017), em que a assistência individualizada acadêmica permite que os suportes sejam mais flexíveis e, portanto, podem atender a uma gama mais diversa de necessidades dos estudantes com TEA. Muitos estudantes com TEA revelaram preferência por esse tipo de apoio acadêmico individualizado, por considerá-los úteis, pois eles possuem maior tendência a passarem por desafios acadêmicos e não acadêmicos significativos (JANSEN et al., 2017).

O estudo de Anderson e Butt (2017) evidenciou alguns dos problemas mais comuns vivenciados por universitários com TEA. Dentre os principais problemas, foi possível 
identificar: 1- Dificuldades acadêmicas: problemas para compreensão de conceitos abstratos e ambíguos, falta de habilidade organizacional e de planejamento; tendência à procrastinação; objeção a trabalhos em grupo; problemas com habilidades sociais, durante as aulas. 2- Dificuldades não acadêmicas: ansiedade, socialização, depressão, Disfunções de Integração Sensorial e a execução de atividades do cotidiano.

Levando em conta os dados do cenário nacional e internacional, bem como políticas públicas promulgadas a respeito da inclusão e acessibilidade de estudantes com TEA, a presente pesquisa tem $\mathrm{o}$ intuito de responder à seguinte pergunta norteadora: $\mathrm{O}$ que as evidências científicas nacionais têm destacado sobre a inclusão de estudantes com TEA no ES?

Assim, buscou-se analisar o processo de formação do universitário com TEA, com ênfase em seu acesso, ingresso e permanência no ES, nas instituições educacionais brasileiras.

\section{Metodologia}

A Revisão Integrativa (RI) é um método de pesquisa considerado pilar da Prática Baseada em Evidências, pois possibilita aos pesquisadores tomar decisões, ligando a teoria à prática e reunindo os melhores resultados de pesquisa. Constitui um método que viabiliza a construção de uma ampla análise da literatura e possíveis reflexões sobre as lacunas presentes, a fim de instigar futuros estudos acerca da temática (MENDES; SILVEIRA; GALVÃO, 2008; SOUZA; SILVA; CARVALHO, 2010; ERCOLE; MELO; ALCOFORADO, 2014).

Segundo Ercole, Melo e Alcoforado (2014), esse tipo de revisão da literatura almeja fundamentar teórica e cientificamente um determinado objetivo, no qual a premissa da pesquisa bibliográfica se baseia na própria experiência dos pesquisadores.

Neste estudo, foram cumpridas seis fases indicadas pela literatura científica para a Revisão Integrativa: 1) identificação do tema e elaboração da pergunta norteadora; 2) estabelecimento de critérios de inclusão e exclusão de estudos e busca da amostragem na literatura; 3) coleta de dados, definindo claramente o que se pretende extrair dos estudos selecionados, categorizando-os; 4) avaliação crítica dos estudos selecionados, interpretação e discussão dos resultados; 5) síntese do conhecimento; e, por fim, 6) apresentação da Revisão Integrativa (MENDES; SILVEIRA; GALVÃO, 2008; SOUZA; SILVA; CARVALHO, 2010; ERCOLE; MELO; ALCOFORADO, 2014). 
http://dx.doi.org/10.5902/1984686X64322

A princípio, foi delimitada a temática de interesse, definindo-se a pergunta norteadora e o objetivo principal deste estudo. Assim, esta investigação foi direcionada pelo seguinte questionamento: $O$ que as evidências científicas nacionais têm destacado sobre a inclusão de estudantes com TEA no ES?

Ainda nessa fase inicial, foi possível fixar os critérios de elegibilidade adotados e as estratégias de busca nas bases de dados do Portal Regional da Biblioteca Virtual em Saúde (BVS), da Scientific Electronic Library Online (Scielo) e dos Periódicos da Coordenação de Aperfeiçoamento de Pessoal de Nível Superior (CAPES). As buscas nas bases de dados ocorreram em dezembro de 2020, tendo sido utilizados os seguintes descritores: ensino superior, educação superior, universidade, autismo, transtorno do espectro autista, transtorno autístico, combinados entre si e usando o operador booleano AND escrito em letras maiúsculas.

Os artigos selecionados para a Revisão Integrativa atenderam aos seguintes critérios de inclusão: abordar a inclusão em nível superior; estar direcionado aos estudantes universitários com TEA; estar relacionado a estudos que contemplem IES Brasileiras; estar escrito em Língua Portuguesa. Foram excluídos os seguintes estudos: artigos repetidos entre as bases de dados consultadas; artigos de revisão de literatura; artigos que se referiam a outros estudantes públicos-alvo da Educação Especial, sem ser exclusivamente estudantes universitários com TEA.

A busca foi realizada por duas das autoras deste estudo, em servidores distintos, sendo que ambas as pesquisadoras alcançaram os mesmos resultados. Na tentativa de resgatar todo o material produzido, não foi definido o espaço temporal para a coleta de amostragem.

Após a coleta de dados nas bases de dados, a análise do material selecionado obedeceu às seguintes etapas: 1) leitura dos títulos e resumos dos artigos, para verificar se atendiam aos critérios de inclusão referidos; 2) eliminação dos artigos duplicados; 3) leitura completa dos artigos que cumpriram os requisitos da etapa anterior.

Com base nos resultados obtidos, primeiramente foi feita a análise descritiva, considerando-se a quantidade de produções, título do estudo, ano de publicação, periódico, autores e objetivos. Também foi realizada a busca de conteúdos relacionados à formação dos autores de cada estudo, na Plataforma Lattes, empregando-se o nome completo de cada um deles, para se obter as informações. Posteriormente, foi proposta a análise de categorias específicas pertinentes ao objetivo deste estudo, entre as quais se destacam: 
http://dx.doi.org/10.5902/1984686X64322

principais resultados do estudo; conclusões; procedimentos metodológicos utilizados nos estudos; número de estudantes com TEA; idade dos universitários identificados no estudo; situação de matrícula; cursos em que eles estavam matriculados; categoria administrativa das universidades; dificuldades observadas na inclusão do estudante com TEA no ES; estratégias para inclusão do aluno com TEA no ES; sugestões para estudos futuros e, por fim, possíveis limitações desta Revisão Integrativa.

\section{Resultados}

Por meio das buscas efetuadas no início de dezembro de 2020, nas bases de dados acima mencionadas, foi possível resgatar um total de 33 artigos, conforme pode ser visto no quadro abaixo:

Quadro 1 - Estratégias de pesquisa utilizadas nas bases de dados selecionadas.

\begin{tabular}{|c|c|c|c|c|}
\hline $\begin{array}{l}\text { Base de } \\
\text { dados }\end{array}$ & $\begin{array}{l}\text { Procedimentos da } \\
\text { Pesquisa }\end{array}$ & $\begin{array}{l}\text { Termos livres/ } \\
\text { Palavras-chave }^{1}\end{array}$ & $\begin{array}{l}\text { Descritores sugeridos } \\
\text { pela base de dados }\end{array}$ & $\begin{array}{c}\text { Amostragem } \\
\text { de Artigos }\end{array}$ \\
\hline $\begin{array}{l}\text { Portal } \\
\text { Regional } \\
\text { da BVS }\end{array}$ & $\begin{array}{l}\text { Seleção "Título, resumo, } \\
\text { assunto". Seleção do } \\
\text { filtro idioma em } \\
\text { Português. Acionamos a } \\
\text { "Busca Avançada". } \\
\text { Na opção "Descritores" } \\
\text { sugeridos } \\
\text { "DeCS/MeSH" e a } \\
\text { seleção do filtro idioma } \\
\text { em Português. }\end{array}$ & $\begin{array}{l}\text { ensino superior } \\
\text { AND autismo }\end{array}$ & $\begin{array}{l}\text { Educação Superior AND } \\
\text { Transtorno Autístico }\end{array}$ & 6 \\
\hline SciELO & $\begin{array}{c}\text { A opção "Todos os } \\
\text { índices" foi acionada. A } \\
\text { opção "Busca } \\
\text { avançada" foi utilizada, } \\
\text { com o campo "Todos os } \\
\text { índices" e filtro idioma } \\
\text { em Português. }\end{array}$ & $\begin{array}{l}\text { Ensino superior } \\
\text { AND autismo/ } \\
\text { Transtorno do } \\
\text { espectro autista } \\
\text { AND universidade }\end{array}$ & * & 7 \\
\hline \multirow[t]{2}{*}{$\begin{array}{l}\text { Periódico } \\
\text { s da } \\
\text { CAPES }\end{array}$} & $\begin{array}{l}\text { Selecionamos a "Busca } \\
\text { Avançada". Data de } \\
\text { publicação "Qualquer } \\
\text { ano". Tipo de Material: } \\
\text { "Artigos" } \\
\text { Idioma: "Português" }\end{array}$ & $\begin{array}{l}\text { Ensino superior } \\
\text { AND transtorno do } \\
\text { espectro autista }\end{array}$ & * & 17 \\
\hline & & TOTAL & & 22 \\
\hline
\end{tabular}

Fonte: Produção das autoras (2020).

Legenda: *As bases de dados não disponibilizam a ferramenta Descritores. 
Depois de concluído o levantamento bibliográfico, foi feita a leitura dos títulos e resumos dos artigos com a finalidade de identificar aqueles que atendiam aos critérios de inclusão do estudo. Foram descartados 24 artigos, como mostra o seguinte fluxograma:

Figura 1 - Fluxograma dos artigos recuperados nas bases de dados selecionadas.

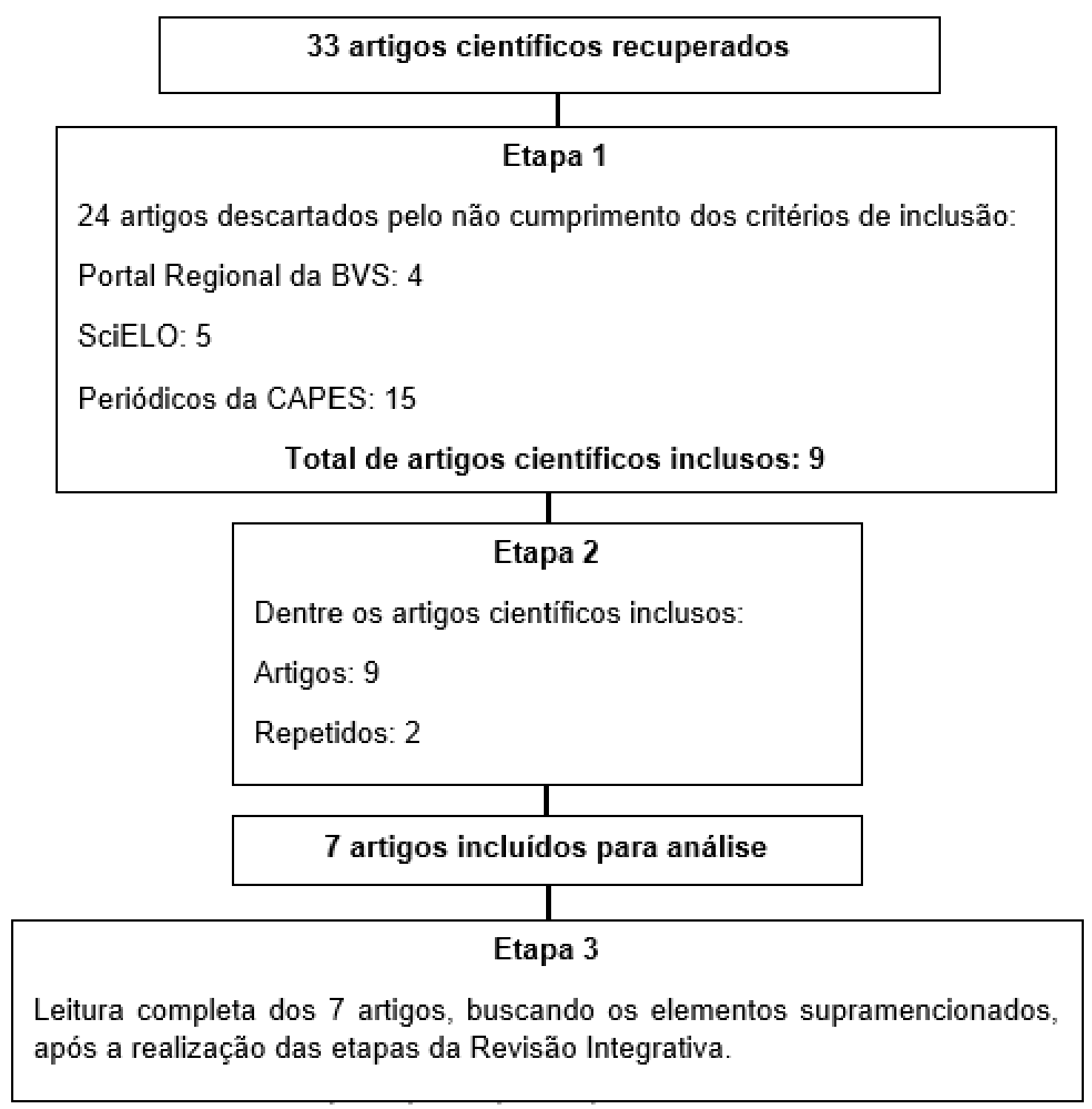

Fonte: Produção das autoras (2020).

O corpus final de análise que compõe esta Revisão Integrativa, seguindo os critérios já reportados, encontra-se caracterizado no Quadro 2: 
http://dx.doi.org/10.5902/1984686X64322

Quadro 2 - Síntese do corpus final selecionado para análise.

(continua)

\begin{tabular}{|c|c|c|c|c|}
\hline №. & Título do artigo & Autores & Periódico/Ano & Objetivo \\
\hline 1 & $\begin{array}{l}\text { Consultoria Colaborativa } \\
\text { no Ensino Superior, tendo } \\
\text { por foco um estudante } \\
\text { com Transtorno do } \\
\text { Espectro Autista. }\end{array}$ & $\begin{array}{l}\text { Grace Cristina } \\
\text { Ferreira } \\
\text { Donatti, Vera } \\
\text { Lucia Messias } \\
\text { Fialho } \\
\text { Capellini }\end{array}$ & $\begin{array}{l}\text { Revista lbero- } \\
\text { Americana de } \\
\text { Estudos em } \\
\text { Educação } \\
\text { Set. } 2018\end{array}$ & $\begin{array}{l}\text { Descrever os procedimentos de } \\
\text { uma consultoria colaborativa } \\
\text { realizada por um profissional } \\
\text { especialista, em parceria com } \\
\text { gestores universitários, com } \\
\text { docentes do curso superior de } \\
\text { Matemática, tendo por foco um } \\
\text { estudante com Transtorno de } \\
\text { Espectro Autista. }\end{array}$ \\
\hline 2 & $\begin{array}{l}\text { Escolarização das } \\
\text { pessoas com Transtorno } \\
\text { do Espectro Autista (TEA) } \\
\text { em idade adulta: relatos e } \\
\text { perspectivas de pais e } \\
\text { cuidadores de adultos } \\
\text { com TEA. }\end{array}$ & $\begin{array}{l}\text { Fernanda } \\
\text { Duarte Rosa, } \\
\text { Thelma } \\
\text { Simões } \\
\text { Matsukura, } \\
\text { Carolina } \\
\text { Elisabeth } \\
\text { Squassoni }\end{array}$ & $\begin{array}{l}\text { Cad. Bras. Ter. } \\
\text { Ocup. } \\
\text { Mar. } 2019\end{array}$ & $\begin{array}{l}\text { Identificar perspectivas de } \\
\text { familiares de adultos com TEA, } \\
\text { em relação às instituições que se } \\
\text { propõem dar atenção aos autistas } \\
\text { na vida adulta. Objetivou também } \\
\text { identificar como foi o percurso } \\
\text { escolar, os aspectos positivos e } \\
\text { desafios, sob o ponto de vista de } \\
\text { seus familiares. }\end{array}$ \\
\hline 3 & $\begin{array}{l}\text { Perfil acadêmico dos } \\
\text { estudantes com } \\
\text { Transtorno do Espectro } \\
\text { Autista matriculados no } \\
\text { Ensino Superior. }\end{array}$ & $\begin{array}{l}\text { Solange } \\
\text { Cristina da } \\
\text { Silva, Daniela } \\
\text { Ribeiro } \\
\text { Schneider, } \\
\text { Erikson } \\
\text { Kaszubowiski, } \\
\text { Adriano } \\
\text { Henrique } \\
\text { Nuernberg }\end{array}$ & $\begin{array}{l}\text { Revista } \\
\text { Educação } \\
\text { Especial } \\
\text { Set. } 2019\end{array}$ & $\begin{array}{l}\text { Mapear o perfil socioacadêmico } \\
\text { dos estudantes com Transtorno } \\
\text { do Espectro Autista (TEA) } \\
\text { matriculados no Ensino Superior } \\
\text { em } 2016 \text {. }\end{array}$ \\
\hline 4 & $\begin{array}{l}\text { Tem um estudante autista } \\
\text { na minha turma! E agora? } \\
\text { O diário reflexivo } \\
\text { promovendo a } \\
\text { sustentabilidade } \\
\text { profissional do } \\
\text { desenvolvimento de } \\
\text { oportunidades } \\
\text { pedagógicas para a } \\
\text { inclusão. }\end{array}$ & $\begin{array}{l}\text { Marta Luciane } \\
\text { Fischer }\end{array}$ & $\begin{array}{l}\text { Rev. Bras. Ed. } \\
\text { Esp. } \\
\text { Out. } 2019\end{array}$ & $\begin{array}{l}\text { Avaliar, por meio da análise } \\
\text { sistemática do conteúdo, três } \\
\text { práticas registradas conforme } \\
\text { premissas e argumentos práticos } \\
\text { no ensino com e sem estudantes } \\
\text { autistas. }\end{array}$ \\
\hline 5 & $\begin{array}{l}\text { Experiências acadêmicas } \\
\text { de estudantes } \\
\text { universitários com } \\
\text { Transtorno do Espectro } \\
\text { Autista: uma análise } \\
\text { interpretativa dos relatos. }\end{array}$ & $\begin{array}{l}\text { Ana Gabriela } \\
\text { Olivati, Lucia } \\
\text { Pereira Leite }\end{array}$ & $\begin{array}{l}\text { Rev. Bras. Ed. } \\
\text { Esp. } \\
\text { Out. } 2019\end{array}$ & $\begin{array}{l}\text { Descrever a experiência } \\
\text { acadêmica de seis estudantes, } \\
\text { com esse diagnóstico, } \\
\text { regularmente matriculados em } \\
\text { uma universidade pública no } \\
\text { estado de São Paulo. }\end{array}$ \\
\hline
\end{tabular}


Quadro 2 - Síntese do corpus final selecionado para análise.

(conclusão)

\begin{tabular}{|c|c|c|c|c|}
\hline №. & Título do artigo & Autores & Periódico/Ano & Objetivo \\
\hline 6 & $\begin{array}{l}\text { Estudantes com } \\
\text { Transtorno do Espectro } \\
\text { Autista no Ensino } \\
\text { Superior: } \\
\text { analisando dados do } \\
\text { INEP }\end{array}$ & $\begin{array}{l}\text { Solange } \\
\text { Cristina da } \\
\text { Silva, Daniela } \\
\text { Ribeiro } \\
\text { Schneider, } \\
\text { Erikson } \\
\text { Kaszubowiski, } \\
\text { Adriano } \\
\text { Henrique } \\
\text { Nuernberg }\end{array}$ & $\begin{array}{l}\text { Psicologia } \\
\text { Escolar e } \\
\text { Educacional } \\
\text { Out. } 2020\end{array}$ & $\begin{array}{l}\text { Mapear o perfil sociodemográfico } \\
\text { dos estudantes com Transtorno } \\
\text { do Espectro Autista } \\
\text { (TEA) matriculados no ES em } \\
\text { 2016, a partir dos microdados do } \\
\text { INEP. }\end{array}$ \\
\hline 7 & $\begin{array}{l}\text { Inclusão e permanência } \\
\text { de universitários com } \\
\text { diagnóstico de } \\
\text { transtorno do espectro } \\
\text { autista: discussões } \\
\text { acerca de barreiras } \\
\text { linguísticas }\end{array}$ & $\begin{array}{l}\text { Patrícia Tusset } \\
\text { da Silveira, } \\
\text { Lais Oliva } \\
\text { Donida, Ana } \\
\text { Paula Santana }\end{array}$ & $\begin{array}{l}\text { Avaliação } \\
\text { Nov. } 2020\end{array}$ & $\begin{array}{l}\text { Analisar as condições de acesso } \\
\text { e permanência de pessoas com } \\
\text { TEA na Universidade, em função } \\
\text { das queixas linguísticas } \\
\text { apresentadas por tais estudantes. }\end{array}$ \\
\hline
\end{tabular}

Fonte: Produção das autoras (2020).

A partir da busca sistemática por publicações de artigos sobre a inclusão, ao nível superior, de estudantes universitários com TEA, foi possível identificar 7 artigos que atendiam aos critérios de elegibilidade. Há escassez de estudos sobre o processo de inclusão desses universitários, no Brasil, sendo os artigos resgatados frutos de pesquisas recentes, sendo 1 estudo do ano de 2018, 4 estudos de 2019 e 2 estudos de 2020.

Considerando a quantidade de participantes, 6 pesquisas especificaram o número de sujeitos que foram envolvidos no estudo. Contudo, a pesquisa de Donatti e Capellini (2018) definiu os participantes como sendo um grupo de indivíduos caracterizado por gestores e professores, sem quantificá-los. O total de participantes descritos nos estudos envolveram: 69 cuidadores de estudantes com TEA, 1228 universitários com TEA, 140 universitários neurotípicos, 1 profissional especialista, 1 docente universitário, 1 grupo de docentes e gestores não quantificados, bem como um número não identificado de fonoaudiólogos que acompanharam estudantes com TEA.

Com relação ao número expressivo de universitários com TEA, destaca-se que 1217 estudantes estão presentes em microdados das pesquisas de Silva e colaboradores (2019 e 2020), obtidos no Censo da Educação Superior do INEP ${ }^{3}$ de 2016, 6 estudantes têm sua experiência acadêmica descrita pelas pesquisadoras Olivati e Leite (2019), 2 estudantes são contemplados no estudo de Fischer (2019), o qual visou a aplicar práticas pedagógicas e de ensino inclusivas, 1 estudante é alvo de um trabalho de consultoria 
http://dx.doi.org/10.5902/1984686X64322

colaborativa (DONATTI; CAPELLINI, 2018) e 2 estudantes participaram de avaliações fonoaudiológicas (SILVEIRA; DONIDA; SANTANA, 2020).

As localidades em que foram efetuados os estudos concentram-se nas regiões Sul e Sudeste, sendo 3 pesquisas no interior do estado de São Paulo e as outras quatro em estados do Sul do país.

Quanto aos procedimentos metodológicos dos estudos, 5 artigos se caracterizaram como qualitativos e 2 como quantitativos. No que concerne aos estudos qualitativos Donatti e Capellini (2018) fizeram um relato de caso envolvendo a consultoria colaborativa; Rosa, Matsukura e Squassoni (2019) utilizaram o método survey, a fim de conhecer o cotidiano de adultos com TEA, por meio da percepção de seus familiares; Fisher (2019) realizou uma análise sistemática de três práticas pedagógicas registradas em diário reflexivo de um docente universitário sem formação em Educação Especial, enquanto os trabalhos de Olivati e Leite (2019) e de Silveira, Donida e Santana (2020) empregaram a entrevista para identificar tópicos relacionados ao ingresso na graduação, permanência, acessibilidade, relacionamentos e sugestões de melhorias, no contexto universitário dos estudantes com TEA. Em relação às pesquisas de caráter quantitativo, Silva e colaboradores $(2019,2020)$ efetuaram estudos de caráter exploratório-descritivo, resgatando dados sobre o processo de inclusão dos estudantes universitários com TEA no site do INEP, relativos ao ano de 2016.

Por fim, o Quadro 3 apresenta resultados e conclusões referentes aos estudos mencionados.

Quadro 3: Resultados dos artigos selecionados.

(continua)

\begin{tabular}{|c|l|l|}
\hline Artigo & \multicolumn{1}{|c|}{ Resultados } & \multicolumn{1}{|c|}{ Conclusões } \\
\hline 1 & $\begin{array}{l}\text { A consultoria colaborativa possibilitou a } \\
\text { identificação das necessidades de apoio } \\
\text { nas tarefas acadêmicas do estudante, com } \\
\text { base na implementação de procedimentos } \\
\text { relacionados à trajetória universitária do } \\
\text { estudante em questão. }\end{array}$ & $\begin{array}{l}\text { Perante o crescente número de estudantes com } \\
\text { necessidades educacionais nas universidades, } \\
\text { faz-se necessário implementar ações } \\
\text { educacionais inclusivas, a partir de mecanismos } \\
\text { de apoio técnico, direcionadas ao estudante } \\
\text { com necessidades educacionais especiais e ao } \\
\text { corpo docente envolvido, procurando atender, } \\
\text { no processo de formação continuada, aos } \\
\text { desafios de transformar práticas do exercício } \\
\text { docente. }\end{array}$ \\
\hline
\end{tabular}


http://dx.doi.org/10.5902/1984686X64322

Quadro 3: Resultados dos artigos selecionados.

(continua)

\begin{tabular}{|c|c|c|}
\hline Artigo & Resultados & Conclusões \\
\hline 2 & $\begin{array}{l}\text { Um número reduzido de estudantes com } \\
\text { TEA conseguiu frequentar o ensino regular, } \\
\text { na idade adulta, e um número ainda menor } \\
\text { deles frequentou o ES, sendo estes } \\
\text { representados por uma parcela da } \\
\text { população que apresenta boas condições } \\
\text { socioeconômicas e de acesso a serviços } \\
\text { de suporte. }\end{array}$ & $\begin{array}{l}\text { Devido ao número reduzido de estudantes com } \\
\text { TEA que alcançaram o ES, torna-se possível } \\
\text { constatar a importância de um adequado ensino } \\
\text { profissionalizante, o qual promova o preparo e } \\
\text { oportunize a inserção desses estudantes no } \\
\text { mercado de trabalho. Destaca-se a necessidade } \\
\text { de locais para convivência, realização de } \\
\text { terapias multidisciplinares, acolhimento às } \\
\text { famílias, atividades de profissionalização para } \\
\text { os adultos com TEA, atendimento } \\
\text { individualizado e a presença de profissionais } \\
\text { qualificados. }\end{array}$ \\
\hline 3 & $\begin{array}{l}\text { Em 2016, foram matriculados } 546 \\
\text { estudantes identificados com TEA, em } \\
\text { cursos superiores, no Brasil. A maioria das } \\
\text { matrículas se fez em instituições privadas, } \\
\text { sendo o vestibular a forma mais comum } \\
\text { para o ingresso desses estudantes, } \\
\text { seguido pelo ENEM. } \\
\text { Quanto à taxa de evasão, pode-se } \\
\text { perceber que os estudantes com TEA } \\
\text { "trancam" a matrícula com menos } \\
\text { frequência que os estudantes neurotípicos. }\end{array}$ & $\begin{array}{l}\text { Há um duplo desafio, no que concerne ao } \\
\text { acesso e permanência de estudantes com TEA } \\
\text { nas IES, sendo o primeiro relacionado à lógica } \\
\text { de políticas públicas e o segundo, de natureza } \\
\text { interna, ligado a algumas estratégias } \\
\text { necessárias como facilitadoras no processo de } \\
\text { inclusão e acessibilidade dos estudantes com } \\
\text { TEA. }\end{array}$ \\
\hline 4 & $\begin{array}{l}\text { O diário reflexivo atuou como um } \\
\text { importante instrumento para reflexão de } \\
\text { práticas pedagógicas com foco nos } \\
\text { estudantes universitários com TEA, } \\
\text { auxiliando na tomada de decisão em sala } \\
\text { de aula, lidando com dilemas } \\
\text { desorientadores e instigando } \\
\text { transformação positiva do indivíduo, } \\
\text { vinculada à aprendizagem. }\end{array}$ & $\begin{array}{l}\text { A prática pedagógica reflexiva conduziu à } \\
\text { melhor compreensão do processo educacional, } \\
\text { considerando as necessidades dos estudantes } \\
\text { com TEA. Foi estabelecido um canal de } \\
\text { comunicação e de abertura ao relacionamento } \\
\text { de confiança mútua, que naturalmente ensejou } \\
\text { encontrar soluções nas diversas situações } \\
\text { vivenciadas. Nota-se a importância em } \\
\text { direcionar a atenção para a efetividade dos } \\
\text { processos de comunicação e a flexibilidade do } \\
\text { sistema educacional, em prol do } \\
\text { desenvolvimento pessoal e profissional de todos } \\
\text { os estudantes. }\end{array}$ \\
\hline 5 & $\begin{array}{l}\text { Por meio dos relatos obtidos dos } \\
\text { participantes estudantes do ES com o } \\
\text { diagnóstico de TEA, foram classificados } \\
\text { três grandes núcleos de significação: a) } \\
\text { ensino básico: heterogeneidade acadêmica } \\
\text { e experiências interacionais pobres; b) } \\
\text { controvérsias entre o interesse pela } \\
\text { graduação e o despreparo do contexto } \\
\text { universitário; c) necessidades de mudança } \\
\text { no âmbito singular e social. }\end{array}$ & $\begin{array}{l}\text { Identificaram-se as dificuldades e os desafios } \\
\text { acadêmicos enfrentados pelos universitários } \\
\text { com TEA. A trajetória destes foi marcada pela } \\
\text { persistência diante dos obstáculos sociais, } \\
\text { metodológicos e individuais. Os suportes } \\
\text { oferecidos pelas instituições foram deficitários, } \\
\text { tanto na identificação das necessidades } \\
\text { educacionais especiais quanto na proposição de } \\
\text { estratégias facilitadoras que contribuíssem para } \\
\text { o sucesso dos estudantes na universidade. }\end{array}$ \\
\hline
\end{tabular}


http://dx.doi.org/10.5902/1984686X64322

Quadro 3: Resultados dos artigos selecionados.

(conclusão)

\begin{tabular}{|c|c|c|}
\hline Artigo & Resultados & Conclusões \\
\hline 6 & $\begin{array}{l}\text { Constatou-se que a maior parte dos } \\
\text { estudantes com TEA são do sexo } \\
\text { masculino. Em relação aos dados sobre } \\
\text { cor/raça, a maioria dos universitários } \\
\text { declarou-se branca. Os dados com } \\
\text { imputação trouxeram mudanças } \\
\text { significativas quanto à localização por } \\
\text { região dos estudantes, identificando-se a } \\
\text { primazia destes na região Nordeste, não } \\
\text { mais na região Sudeste. Por fim, a média } \\
\text { de idade de estudantes com TEA, no ES, é } \\
\text { de } 27,6 \text { anos. }\end{array}$ & $\begin{array}{l}\text { Embora haja uma fragilidade nos dados oficiais } \\
\text { disponíveis, a pesquisa pôde mapear de forma } \\
\text { consistente o perfil sociodemográfico dos } \\
\text { universitários com TEA. Assim, tais dados } \\
\text { devem ser levados em conta, ao se pensar } \\
\text { sobre políticas públicas e ações afirmativas que } \\
\text { objetivem ações inclusivas para esse público. }\end{array}$ \\
\hline 7 & $\begin{array}{l}\text { Os resultados apontaram que as questões } \\
\text { linguísticas apresentam impacto no } \\
\text { comprometimento e rendimento escolar } \\
\text { dos universitários com TEA. As questões } \\
\text { linguísticas, ainda, impactam no } \\
\text { relacionamento interpessoal desses } \\
\text { estudantes, isolando-os em sala de aula e } \\
\text { relegando a eles papéis secundários nas } \\
\text { atividades. Há várias barreiras que se } \\
\text { impõem, no contexto dos universitários } \\
\text { com TEA, sejam elas atitudinais, sejam } \\
\text { linguísticas, } \\
\text { comunicacionais/informacionais. }\end{array}$ & $\begin{array}{l}\text { Pôde-se concluir que são necessárias ações } \\
\text { interdisciplinares que promovam debates na } \\
\text { Educação Superior acerca do tema de inclusão. } \\
\text { O papel do Núcleo de Acessibilidade se mostra } \\
\text { de fundamental importância para a permanência } \\
\text { dos estudantes com TEA. A Fonoaudiologia } \\
\text { Educacional envolve uma variedade de } \\
\text { propostas que podem auxiliar no processo de } \\
\text { inclusão desses universitários, para } \\
\text { proporcionar um apoio no planejamento das } \\
\text { atividades ao processo institucional. }\end{array}$ \\
\hline
\end{tabular}

Fonte: Produção das autoras (2020).

\section{Discussão}

Os estudos incluídos nesta análise foram realizados por pesquisadores da área da Saúde e da Educação, cujas formações acadêmicas são nas seguintes áreas: Psicologia (4), Terapia ocupacional (3), Fonoaudiologia (5), Pedagogia (1), Biologia/Artes Plásticas (1). Esses pesquisadores se caracterizam por serem docentes e discentes envolvidos em Programas de Pós-Graduação nas áreas de Educação, Educação Especial, Psicologia e Estudos da Linguagem.

Com relação aos universitários com TEA participantes das pesquisas, a média de idade é de 26 anos, corroborando a análise de Silva e colaboradores (2019), que observou maior recorrência de matrículas ativas dos universitários com TEA na faixa etária entre 20 e 29 anos.

De acordo com os dados censitários presentes em Silva e colaboradores (2019), os cursos de preferência escolhidos pelos estudantes com TEA são Ciências Sociais, Negócios e Direito. No entanto, as investigações de Donatti e Capellini (2018), Fischer (2019), Olivati e Leite (2019) e Silveira, Donida e Santana (2020) apontaram preferências dos universitários 
http://dx.doi.org/10.5902/1984686X64322

por cursos nas áreas de Ciências Exatas e Biológicas, porém, como a amostra de estudos é reduzida, impossibilita generalizações comparativas.

Com exceção do trabalho de Rosa, Matsukura e Squassoni (2019), o qual não classificou a situação acadêmica dos indivíduos com TEA, os demais estudos identificados nesta Revisão Integrativa indicaram que os estudantes com TEA se encontravam regularmente matriculados em IES, em modalidade presencial e grande parte na categoria administrativa pública. Embora os dados censitários da pesquisa de Silva e colaboradores (2019) tenham revelado um maior índice de matrículas efetuadas em instituições privadas, os autores destacam tal informação como sendo uma fragilidade dos dados obtidos, quando fazem referência aos microdados com imputação e sem imputação, já que, ao mensurá-los sem imputação, as Instituições Universitárias Federais aparecem com percentuais mais elevados em comparação com as Instituições Universitárias privadas.

Silva e colaboradores (2019) apresentam, na análise de sua pesquisa, a existência de discrepâncias nos registros entre os diferentes anos, havendo possíveis vieses que podem interferir nos resultados, como o fato do diagnóstico de TEA ser declarado pelo próprio estudante, no ato da matrícula. Em conformidade com os resultados de Silva e colaboradores (2019), o estudo de Olivati e Leite (2019), ao resgatar a percepção de estudantes com TEA, traz para discussão o desejo desses estudantes de ocultar o seu diagnóstico, por receio de sofrer discriminação, subjugação e estigmatização, afirmando preferir manter-se no anonimato, para não serem reconhecidos como "coitadinho e pobrezinho".

Pesquisadores americanos também ressaltaram a relutância de estudantes universitários com TEA compartilharem o seu diagnóstico, por medo de serem rotulados como deficientes e, consequentemente, serem tomados por incapazes ou diferentes (BOLOURIAN; ZEEDYK; BLACHER, 2018).

Como exemplo de estigmas já incorporados pela comunidade acadêmica, os estudantes com TEA participantes do estudo de Silveira, Donida e Santana (2020) relataram experiências nas quais se sentiram diferentes dos demais, devido às suas particularidades, sendo vistos como incapazes e, muitas vezes, excluídos das atividades em grupo.

Entre as experiências que obtiveram sucesso na inclusão de estudantes com TEA, a pesquisa de Donatti e Capellini (2018) apontou a consultoria colaborativa como um procedimento promissor para o trabalho cooperativo entre as áreas da Educação e da Saúde, não somente no âmbito da intervenção, mas também na prevenção, reflexão e transformação no meio acadêmico através do compartilhamento de saberes. 
http://dx.doi.org/10.5902/1984686X64322

Quanto às políticas públicas inclusivas, é importante considerar os programas governamentais que funcionam como facilitadores para o ingresso das pessoas com deficiência no ES, quer no ensino público, quer no ensino privado (BRASIL, 2001, 2005a).

Algumas iniciativas importantes podem ser encontradas em políticas como a concessão de bolsas por órgãos de fomento, como o $\mathrm{FIES}^{4}$ e PROUNI ${ }^{5}$, além de ser possível contar com programas que estimulam o acesso ao ES, como REUNI, SISU, ENEM. ${ }^{6}$ O programa INCLUIR propõe ações que garantem o acesso das pessoas com deficiência às IES federais (SILVA et. al, 2019).

O trabalho de Silveira, Donida e Santana (2020) exemplifica como ocorre, na ES estudada, o assessoramento aos estudantes com TEA . Entre as estratégias para oferecer 0 acesso aos estudantes com TEA, destaca-se o Núcleo de Acessibilidade, o qual acompanha os estudantes Público-Alvo da Educação Especial desde a inscrição para o vestibular até o seu ingresso e permanência na universidade onde são acompanhados por profissionais que avaliam as necessidades, apoiam as atividades de docentes e discentes e realizam encaminhamentos para outros serviços quando necessário.

Os estudos identificados nesta revisão reforçam a tese de que, após o ingresso, é necessária a continuidade de ações, a fim de garantir, de fato, a inclusão do estudante com TEA na universidade. Esse resultado também é apontado pela literatura. Incluir alunos com deficiência nas IES exige uma rede de suporte para a permanência e sucesso na formação acadêmica, a partir do estabelecimento de adequações para o atendimento aos estudantes com deficiências (LARA; SEBASTIÁN-HEREDERO, 2020).

Nas pesquisas oriundas das IES estaduais, não foi possível encontrar programas de suporte e acessibilidade à permanência dos universitários com TEA, como, por exemplo, os Núcleos de Apoio aos estudantes com TEA (OLIVATI; LEITE 2019). Nas IES privadas, também não foram identificados núcleos de apoio a universitários, entretanto, a pesquisa de Fischer (2019) revelou a iniciativa de um docente universitário, sem formação em Educação Especial, em buscar estratégias inclusivas para melhor atender às singularidades dos universitários com TEA.

Ainda em relação aos suportes que visam a garantir a permanência do estudante com TEA na universidade, Ciantelli e Leite (2016) afirmam que, entre os papéis das IES, é fundamental a responsabilidade de criar políticas públicas próprias, as quais objetivem a acessibilidade de estudantes com deficiência. Essas evidências sinalizam possíveis 
http://dx.doi.org/10.5902/1984686X64322

dificuldades no enfrentamento das barreiras observadas na comunidade acadêmica, especialmente nas IS estaduais e privadas, para a inclusão dos universitários com TEA.

A necessidade de estratégias inclusivas foi mencionada, igualmente, pelos docentes participantes da pesquisa de Donatti e Capellini (2018). Os referidos docentes relataram que foi determinante o uso de estratégias constantes de sondagem da aprendizagem do estudante com TEA, tendo em vista que o insucesso recorrente pode levar ao abandono. A reavaliação periódica é fundamental, pois a maioria dos universitários com TEA ingressa no ES, mas não consegue se formar, devido às inúmeras barreiras sociais ou educacionais que dificultam o sucesso acadêmico (HILLIER et. al, 2017). O amplo índice de estudantes com TEA matriculados na universidade e que não conseguem se formar também é destaque na investigação de Bolourian e colaboradores (2018).

No que diz respeito às dificuldades encontradas ao longo do processo da formação dos universitários, foram percebidos certos entraves, tais como: a escassez de evidências científicas que abordem práticas capazes de favorecer a inclusão de estudantes universitários com TEA (DONATTI; CAPELLINI, 2018; SILVA et. al., 2018, 2020; OLIVATI; LEITE, 2019; SILVEIRA; DONIDA; SANTANA, 2020); os complicadores associados à interação social (DONATTI; CAPELLINI, 2018; SILVA et. al., 2019; FISHER, 2019; OLIVATI; LEITE, 2019); as dificuldades de comunicação do estudante com TEA (DONATTI; CAPELLINI, 2018; SILVA et. al., 2019; FISHER, 2019; OLIVATI; LEITE, 2019); as práticas pedagógicas desencadeadoras de ansiedade (DONATTI; CAPELLINI, 2018; FISHER, 2019); o bullying e o sofrimento acadêmico (OLIVATI; LEITE, 2019; SILVEIRA; DONIDA; SANTANA, 2020).

Diante das dificuldades mencionadas, ações e estratégias foram sugeridas para superação dos obstáculos identificados. Os autores supracitados frisaram ser primordial considerar as particularidades de cada indivíduo, pois suas necessidades eram específicas. Dessa forma, é relevante destacar que não existe um padrão único capaz de atender às necessidades de todos os estudantes, docentes e comunidade acadêmica, para a inclusão no ES. É preciso estabelecer um relacionamento pautado na comunicação, confiança e abertura, para a construção de vínculos que promovam o conhecimento, por parte da comunidade acadêmica, quanto às especificidades de seus estudantes (FISCHER, 2019).

Segundo Rosa, Matsukura e Squassoni (2019), a inserção de profissionais de apoio que desempenham papéis de facilitadores e mediadores pode contribuir para o desenvolvimento de habilidades sociais e cognitivas de pessoas com TEA, a fim de promover o auxílio na adaptação de rotinas e de currículos direcionados às necessidades individuais dos 
http://dx.doi.org/10.5902/1984686X64322

estudantes. Do mesmo modo, a parceria interdisciplinar e a consultoria colaborativa mostramse serviços promissores de suporte. Assinala-se que esses apoios podem ser otimizados pelos Núcleos de Acessibilidade das IES.

Tanto a parceria interdisciplinar quanto a consultoria colaborativa respaldam-se pela Lei Brasileira de Inclusão da Pessoa com Deficiência (BRASIL, 2015), englobando todos os níveis de ensino, desde a Educação Infantil até o Superior, devendo-se garantir oportunidades e condições para que as pessoas com deficiência possam iniciar e concluir seus estudos. Assim, a presença de profissionais de apoio torna-se um elemento fundamental, já previsto na Constituição, de sorte a fortalecer positivamente a permanência dos estudantes nas IES.

No que concerne às parcerias de sucesso, a tutoria por pares é uma recomendação mencionada em artigos internacionais, como de Hamilton, Stevens e Girdler (2016) e Anderson e colaboradores (2018). Hamilton, Stevens e Girdler (2016) resgatam essa prática e trazem a definição de tutoria por pares como uma mentoria formalizada, na qual um indivíduo mais experiente desempenha um papel de apoio, supervisionando e estimulando a reflexão e a aprendizagem de uma pessoa menos experiente, de modo a facilitar seu desenvolvimento pessoal e profissional. O trabalho de Anderson e colaboradores (2018) corrobora essa definição e acrescenta que a tutoria favorece o desenvolvimento de habilidades sociais, diminuição da ansiedade, melhora no desempenho acadêmico, autoeficácia e orientação futura.

Bolourian, Zeedyk e Blacher (2018) pontuam que a escola de Ensino Médio pode auxiliar no planejamento de transição para os estudantes com deficiência no neurodesenvolvimento. É importante desenvolver serviços de apoio, com base no modelo social, no qual os futuros estudantes universitários poderão ser mediados por pares para a preparação na educação no ES, minimizando as barreiras e dificuldades desses estudantes.

Nos estudos brasileiros selecionados, a tutoria por pares não foi identificada como uma das estratégias de apoio a inclusão do estudante com TEA. No entanto, foram apresentadas outras estratégias como, por exemplo, a flexibilização nas propostas avaliativas para os universitários com TEA, incluindo as adequações linguísticas nos enunciados, o aceite de respostas orais (com apoio de suportes diversificados), tempo extra para a realização dos testes e oferecimento de apoio na leitura das questões (DONATTI; CAPELLINI, 2018).

Na pesquisa de Fischer (2019), outra estratégia indicada como promissora foi o uso do diário reflexivo como um dos instrumentos para o planejamento e a prática pedagógica, com o objetivo de auxiliar a autorreflexão do trabalho docente; a análise do diário reflexivo 
http://dx.doi.org/10.5902/1984686X64322

favoreceu o uso das seguintes ações do docente com o estudante com TEA: entrega das atividades por escrito, contendo informações claras e objetivas; confecção de infográficos para sintetizar aulas; tempo extra entre professor e aluno, para diálogo e feedback; adaptação da comunicação, empregando textos curtos, uso de imagens e vídeos para apoio aos conteúdos; adaptação das provas.

As estratégias utilizadas, pelo docente, mencionadas no estudo de Fischer (2019) são, igualmente, relatadas na investigação de McKeon, Alpern e Zamenger (2013), com professores universitários da América do Norte. A pesquisa, concretizada em 2013, objetivou apresentar sugestões de diretrizes para facilitar o acesso ao currículo para todos os estudantes, incluindo os com TEA. Os resultados apontam para a necessidade de organização das aulas, buscando-se cumprir o que foi previamente planejado e anunciado pelo professor; organização das atividades, dividindo as grandes e complexas em menores porções; elaboração de materiais de apoio que colaborem para aumentar o foco, recorrendo ao uso das tecnologias, como slides em PowerPoint, emprego de organizadores visuais que contenham informações explícitas, como quadros de "Problema/Solução"; adaptações e variadas formas de avaliação; oferecimento de oportunidades de trabalhos em grupo, para ocorrer engajamento social.

Na pesquisa de Olivati e Leite (2019), os participantes revelaram que mudança de postura por parte dos docentes seria importante para a compreensão das peculiaridades de cada estudante; dessa forma, seria oferecido auxílio mais pontual no acesso ao conteúdo ministrado nas disciplinas. É fundamental lembrar que as barreiras atitudinais podem trazer desafios importantes na compreensão das demandas para a inclusão do estudante com TEA.

Os trabalhos de Gurbuz, Hanley e Riby (2018) e de Bolourian, Zeedyk e Blacher (2018) trazem resultados que comprovam as dificuldades identificadas em relação à mudança de postura dos docentes, no cenário brasileiro. Esses estudos destacam que os universitários com TEA tinham a percepção de que seus professores e colegas de classe não compreendiam suas dificuldades e, consequentemente, não aceitavam suas diferenças. Os estudantes com TEA relataram também que muitos docentes não se preocupavam em como suas especificidades interferiam no seu desempenho acadêmico.

A partir do discorrido nesta discussão, é possível perceber que a educação inclusiva é um desafio para toda a comunidade acadêmica, especialmente para os docentes e para os estudantes com e sem TEA, no ES. Esses resultados implicam a necessidade de refletir em 
consistentes modificações na formação inicial dos docentes, bem como em formação continuada, a fim de embasar tais profissionais a proporcionar ações que eliminem as barreiras encontradas em muitas instituições de ES (CIANTELLI; LEITE, 2016; LARA; SEBASTIAN-HEREDERO, 2020).

Há a necessidade de se investir na formação continuada dos docentes, de modo que possibilite a realização de mediações mais objetivas e intencionais, de modo que eles consigam organizar instrumentos e recursos mediadores externos capazes de garantir a participação efetiva dos estudantes com deficiência nas atividades acadêmicas (TAVARES, 2014).

Dado o número reduzido de estudos publicados no contexto brasileiro, não é possível obter dados suficientes para se examinar até que ponto os achados podem ser generalizáveis. Embora os estudos identificados no cenário nacional forneçam dados importantes sobre a trajetória universitária dos estudantes com TEA, também é possível mapear as diversas fragilidades do contexto universitário acerca da inclusão desses estudantes. É fundamental que pesquisadores e estudantes de Pós-Graduação direcionem esforços para a ampliação dos estudos da inclusão do estudante com TEA no ES, a fim de preencher as lacunas existentes nessa área.

É possível afirmar que ainda são incipientes as evidências, na literatura brasileira, em relação à inclusão do estudante com TEA no ES. Nesse contexto, é relevante considerar que a inclusão de universitários com TEA também no ES apresenta uma projeção ascendente para os próximos anos. Portanto, há uma premência de se investigar as necessidades específicas dos estudantes com TEA (FRIEDMAN; WARFIELD; PARISH, 2013), para implantação de práticas baseadas em evidências científicas de apoio e suporte à inclusão nas universidades brasileiras.

É fundamental o aprofundamento das investigações, considerando-se as características individuais dos estudantes, como, por exemplo, o sexo, a idade, as condições socioeconômicas, entre outras. Isso é importante, porque as necessidades e desafios relatados podem estar igualmente associados a outras diferenças e não necessariamente ao diagnóstico em si (GURBUZ; HANLEY; RIBY, 2018).

Por fim, enfatiza-se que a ampliação de estudos é imprescindível, de sorte a dar sustentação a novas políticas públicas e práticas que considerem os aspectos culturais que fazem parte especificamente das demandas encontradas nas IES do cenário brasileiro. 


\section{Considerações Finais}

Esta Revisão Integrativa da Literatura, cujos resultados desempenham um papel importante na identificação da escassez de estudos sobre a inclusão do estudante universitário com TEA, cumpriu especificamente o objetivo de fornecer um panorama sobre a situação dos alunos e docentes nas universidades brasileiras, no que diz respeito ao tema.

Revelou-se um número restrito de evidências científicas nacionais, as quais demonstram uma lacuna nos estudos especificamente projetados para os estudantes universitários com TEA, no contexto do Brasil. Essa fragilidade pode ser justificada pelo fato de o acesso desse público na universidade ser uma realidade recente, assim como sua inclusão.

Espera-se que, à medida que esse fenômeno se expanda, seja possível identificar novas pesquisas capazes de beneficiar não somente os estudantes com TEA, mas também todo e qualquer universitário que necessite de apoio para atingir, por direito, a sua tão sonhada formação acadêmica.

\section{Referências}

AMERICAN PSYCHIATRIC ASSOCIATION. Manual Diagnóstico e Estatístico de Transtornos Mentais - DSM-5-TR. Porto Alegre: Artmed, 2013.

ANDERSON, Anastasia H. et al. A Systematic Literature Review of Empirical Research on Postsecondary Students with Autism Spectrum Disorder. J Autism Dev. Disord, 2019.

ANDERSON, Connie; BUTT, Catherine. Young Adults on the Autism Spectrum at College: Successes and Stumbling Blocks. J Autism Dev. Disord, 2017.

BOLOURIAN, Yasamine; ZEEDYK, Sasha M.; BLACHER, Jan. Autism and the University Experience: Narratives from Students with Neurodevelopmental Disorders. J Autism Dev Disord, 2018.

BRASIL. Secretaria de Educação Superior e Secretaria de Educação Especial. Política de acessibilidade plena de pessoas com deficiência na educação superior. Diário Oficial da União: seção 1, Brasília, DF, maio de 2008, p.39-40. Disponível em:

http://portal.mec.gov.br/sesu/arquivos/pdf/Incluir/incluir2008.pdf. Acesso em: 07 ago. 2020.

BRASIL. Secretaria Geral. Lei Brasileira de Inclusão da Pessoa com Deficiência (Estatuto da Pessoa com Deficiência). Brasília, DF, 2015. Disponível em: http://www.planalto.gov.br/ccivil_03/_Ato2015-2018/2015/Lei/L13146.htm. Acesso em: 24 jul. 2020. 
http://dx.doi.org/10.5902/1984686X64322

BRASIL. Ministério da Educação. Secretaria de Educação Especial. Política nacional de educação especial na perspectiva da educação inclusiva. Brasília: MEC/SEESP, 2008b.

BRASIL. Ministério da Educação. Instituto Nacional de Estudos e Pesquisas Educacionais Anísio Teixeira. Referenciais de acessibilidade na educação superior e a avaliação in loco no sistema nacional de avaliação da educação superior (SINAES). Brasília, DF: MEC/INEP, 2013a.

BRASIL. Ministério da Educação. Diretrizes Nacionais para a Educação Especial na Educação Básica. Brasília, DF: MEC/SEESP, 2001. Disponível em: www.mec.gov.br/seesp. Acesso em: 09 abr. 2021.

BRASIL. Presidência da República. Lei no11.096, de 13 de janeiro de 2005. Programa Universidade para todos (PROUNI). Brasília, DF: Presidência da República, 2005a. Disponível em: http://www.planalto.gov.br/ccivil_03/_ato2004-2006/2005/lei/L11096.htm. Acesso em: 09 abr. 2021.

BRASIL. Lei no 11.552, de 19 de novembro de 2007. Altera a Lei $n=10.260$, de 12 de julho de 2001, que dispõe sobre o Fundo de Financiamento ao Estudante do Ensino Superior (FIES). Brasília, DF: Presidência da República, 2007. Disponível em: http://www.planalto.gov.br/ccivil_03/_ato2007-2010/2007/Lei/L11552.htm. Acesso em: 14 abr. 2021.

CIANTELLI, Ana Paula Camilo; LEITE, Lúcia Pereira. Ações Exercidas pelos Núcleos de Acessibilidade nas Universidades Federais Brasileiras. Rev. bras. educ. espec., Marília , v. 22, n. 3, p. 413-428, set. 2016. Disponível em:

http://www.scielo.br/scielo.php?script=sci_arttext\&pid=S1413-

65382016000300413\&lng=en\&nrm=iso. Acesso em: 12 abr. 2021.

DONATI, Greice Cristina Ferreira; CAPELLINI, Vera Lucia Messias Fialho. Consultoria colaborativa no ensino superior, tendo por foco um estudante com Transtorno do Espectro Autista. Revista Ibero-Americana de Estudos em Educação, [S.I.], p. 14591470, sep. 2018. Disponível em: https://periodicos.fclar.unesp.br/iberoamericana/article/view/11655. Acesso em 07 ago. 2020.

ERCOLE, Flávia Falci; MELO Laís Samara de; AICOFORADO, Carla Lúcia Goulart Constant. Revisão Sistemática versus Revisão Integrativa. Reme Rev. Min.

Enfermagem, Belo Horizonte, v. 18, n. 1, 1-260. jan./mar. 2014. Disponível em: REME Revista Mineira de Enfermagem - Revisão integrativa versus revisão sistemática. Acesso em: 17 jul. 2020.

FISCHER, Marta Luciane. Tem um Estudante Autista na minha Turma! E Agora? O Diário Reflexivo Promovendo a Sustentabilidade Profissional no Desenvolvimento de Oportunidades Pedagógicas para Inclusão. Rev. bras. educ. espec., Bauru, v. 25, n. 4, p. 535-552, dez. 2019. Disponível em:

http://www.scielo.br/scielo.php?script=sci_arttext\&pid=S1413-

65382019000400535\&lng=en\&nrm=iso. Acesso em: 07 ago. 2020. 
FRIEDMAN, Nora D. B.; WARFIELD, Marji Erickson; PARISH, Susan L. Transition to adulthood for individuals with autism spectrum disorder: Current issues and future perspectives. Neuropsychiatry, v. 3, n. 2, p. 181-192, 2013.

GALVÃO, Taís Freire; PANSANI, Thais de Souza Andrade; HARRAD, David. Principais itens para relatar Revisões sistemáticas e Meta-análises: A recomendação

PRISMA. Epidemiol. Serv. Saúde, Brasília, v. 24, n. 2, p. 335-342, jun. 2015. Disponível em: http://www.scielo.br/scielo.php?script=sci_arttext\&pid=S2237-

96222015000200335\&lng=en\&nrm=iso. Acesso em: 18 jul. 2020.

GURBUZ, Emine; HANLEY, Mary; RIBY, Deborah M. University Students with Autism: The Social and Academic Experiences of University in the UK. J Autism Dev Disord, v. 49, p. 617-631, 2019.

HAMILTON, Josette; STEVENS, Gillian; GIRDLER, Sonya. Becoming a Mentor: The Impact of Training and the Experience of Mentoring University Students on the Autism Spectrum. PLoS ONE, v. 11, n. 4, e0153204, 2016.

HILLIER Ashleigh et al. Supporting university students with autism spectrum disorder. Autism, v. 22, n. 1, p. 20-28, 2018.

JANSEN, Dorien et al. Functioning and participation problems of students with ASD in higher education: Which reasonable accommodations are effective? European Journal of Special Needs Education, v. 32, n. 1, p. 71-88, 2017.

KUDER, S. Jay; ACCARDO, Amy. What Works for College Students with Autism Spectrum Disorder. J Autism Dev Disord., v. 48, n. 3, p. 722-731, 2018.

LARA, P. T.; SEBASTIÁN-HEREDERO, E. Organização do acesso e permanência das pessoas com deficiência no ensino superior a partir da instauração do Programa INCLUIR. Revista on line de Política e Gestão Educacional, Araraquara, v. 24, n. esp2, p. 1137-1164, 2020. Disponível em:

https://periodicos.fclar.unesp.br/rpge/article/view/14337. Acesso em: 12 abr. 2021.

MCKEON, Barbara; ALPERN, Carol S.; ZAGER, Dianne. Promoting academic engagement for college students with autism spectrum disorder. Journal of

Postsecondary Education and Disability, v. 26, p. 353-366, 2013.

OLIVATI, Ana Gabriela; LEITE, Lucia Pereira. Experiências Acadêmicas de Estudantes Universitários com Transtornos do Espectro Autista: uma Análise Interpretativa dos Relatos. Rev. bras. educ. espec., Bauru, v. 25, n. 4, p. 729-746, dez. 2019. Disponível em: http://www.scielo.br/scielo.php?script=sci_arttext\&pid=S141365382019000400729\&Ing=en\&nrm=iso. Acesso em: 07 ago. 2020.

ROSA, Fernanda Duarte; MATSUKURA, Thelma Simões; SQUASSONI, Carolina Elisabeth. Escolarização de pessoas com Transtornos do Espectro Autista (TEA) em idade adulta: relatos e perspectivas de pais e cuidadores de adultos com TEA. Cad. Bras. Ter. Ocup. [on-line], v. 27, n. 2, 2019. Disponível em: http://www.scielo.br/scielo.php?script=sci_arttext\&pid=S252689102019000200302\&lng=en\&nrm=iso. Acesso em: 07 ago. 2020. 
SANTOS, Vivian; ELIAS, Nassim Chamel. Caracterização das Matrículas dos Alunos com Transtorno do Espectro do Autismo por Regiões Brasileiras. Rev. bras. educ. espec., Bauru, v. 24, n. 4, p. 465-482, dez. 2018. Disponível em: http://www.scielo.br/scielo.php?script=sci_arttext\&pid=S1413$65382018000400465 \&$ Ing=en\&nrm=iso. Acesso em: 09 set. 2020.

SILVA, Solange Cristina da et al. Perfil acadêmico dos estudantes com Transtorno do Espectro Autista matriculados no Ensino Superior. Rev. educ. espec. [on-line]. Santa Maria, v. 32, 2019. Disponível em:

https://periodicos.ufsm.br/educacaoespecial/article/view/37699. Acesso em: 07 ago. 2020.

SILVA, Solange Cristina da et al. Estudantes com transtorno do espectro autista no ensino superior: analisando dados do INEP. Psicol. Esc. Educ., Maringá, v. 24, 2020. Disponível em: http://www.scielo.br/scielo.php?script=sci_arttext\&pid=S141385572020000100333\&lng=en\&nrm=iso. Acesso em: 12 dez. 2020.

SILVEIRA, Patrícia Tusset da; DONIDA, Lais Oliva; SANTANA, Ana Paula. Inclusão e permanência de universitários com diagnóstico de transtorno do espectro autista:

discussões acerca de barreiras linguísticas. Avaliação (Campinas), Sorocaba, v. 25, n. 3, p. 659-675, dez. 2020. Disponível em:

http://www.scielo.br/scielo.php?script=sci_arttext\&pid=S1414-

40772020000300659\&Ing=en\&nrm=iso. Acesso em: 12 dez. 2020.

SOUZA, Marcela Tavares de; SILVA, Michelly Dias da; CARVALHO, Rachel de. Revisão integrativa: o que é e como fazer. Einstein, São Paulo, v. 8, n. 1, p. 102-106, mar. 2010. Disponível em: http://www.scielo.br/scielo.php?script=sci_arttext\&pid=S1679$45082010000100102 \&$ Ing=en\&nrm=iso. Acesso em: 18 jul. 2020.

TAVARES, A. P. P. Educação Especial no Ensino Superior: acessibilidade no processo de inclusão escolar, a partir de relatos de acadêmicos com deficiência. 2014. $141 \mathrm{f}$.

Dissertação (Mestrado) - Universidade Estadual de Maringá, Maringá, 2014.

\section{Notas}

1 "Termos livres" e "Palavras-chave" são nomenclaturas adotadas pelos portais Periódicos da CAPES, SciELO Brasil e Portal Regional da BVS, a fim de facilitar a pesquisa e o resgate de estudos relevantes.

2 Dentre as bases de dados elencadas neste estudo, apenas o Portal Regional da BVS possui a opção de busca por "Descritores".

${ }^{3}$ Instituto Nacional de Estudos e Pesquisas Educacionais Anísio Teixeira.

${ }^{4}$ Fundo de Financiamento ao Estudante do Ensino Superior (FIES). Regulamentado pela Lei no 10.260/2001.

5 Programa Universidade para Todos (PROUNI). Regulamentado pela Lei nº11.096/2005a.

6 Programa de Apoio a Planos de Reestruturação e Expansão das Universidades Federais (REUNI); Sistema de Seleção Unificada (SISU); Exame Nacional do Ensino Médio (ENEM).

This work is licensed under a Creative Commons Attribution-NonCommercial 4.0 International (CC BY-NC 4.0) 